\title{
O percurso da bocha paralímpica brasileira: dos Jogos de Mar Del Plata aos Jogos Paralímpicos do Rio de Janeiro
}

The path of brazilian boccia: from the Mar Del Plata Games to the Paralympic Games in Rio de Janeiro

La historia de las boccias paralímpicos brasileña: dos juegos del Mar Del Plata hasta los juegos paralímpicos del Río de Janeiro

Recebido: 03/05/2020 | Revisado: 04/05/2020 | Aceito: 05/05/2020 | Publicado: 12/05/2020

Matheus Jancy Bezerra Dantas

ORCID: https://orcid.org/0000-0003-4743-0510 Universidade Estadual de Campinas - Unicamp, Brasil

E-mail: matheusjancy@gmail.com Thaísa Lucas Filgueira Souza Dantas ORCID: https://orcid.org/0000-0002-9976-3205 Universidade Estadual de Campinas - Unicamp, Brasil E-mail: thaisasdantas@gmail.com José Irineu Gorla

ORCID: https://orcid.org/0000-0003-2099-9643 Universidade Estadual de Campinas - Unicamp, Brasil E-mail: gorla@unicamp.com

\section{Resumo}

O estudo aponta o surgimento do jogo de bocha paralímpica brasileira. A modalidade representa o grande cenário para os atletas com paralisia cerebral e outras deficiências severas. As ousadias do professor Ivaldo Brandão permitiram o surgimento de uma modalidade extremamente vitoriosa. Tem como objetivo investigar o percurso da bocha paralímpica brasileira a partir do I Jogos realizado em Mar Del Plata, na Argentina em 1995 aos Jogos Paralímpicos Rio de Janeiro 2016. Utilizou-se o referencial teórico-metodológico da História Oral com apoio teórico do conceito de acontecimento, embasando-se na análise de fonte oral, que foram relacionadas com os resultados encontrados na revisão bibliográfica. Apesar de ser uma modalidade bastante vitoriosa na atualidade, o caminho percorrido pela 
bocha paralímpica foi marcado pelo descredito nos esportes para a pessoa com paralisia cerebral, pelas dificuldades de participação em competições internacionais, pela falta de equipamentos específicos e os poucos recursos destinados ao esporte para pessoas com deficiência no país. Sua memória evidencia muito mais que uma caminho trilhado por uma modalidade, medalhas e competições, já que registra parte da história do movimento paralímpico brasileiro. Dessa maneira, consideramos que a bocha paralímpica brasileira criou um grande legado, revelado neste trabalho. Espera-se, por meio deste recorte histórico, contribuir com a pesquisa do esporte paralímpico, preservando a memória dos esportes para a pessoa com Paralisia Cerebral, principalmente a bocha paralímpica.

Palavras-chave: História do esporte; Bocha paralímpica; Paralisia cerebral.

\section{Abstract}

The study points to the emergence of the brazilian boccia. The sport represents the great scenario for athletes with cerebral palsy and other severe disabilities. The boldness of teacher Ivaldo Brandão allowed the emergence of an extremely successful modality. It aims to investigate the route of the brazilian boccia from the 1st Games held in Mar Del Plata, Argentina in 1995 to the Rio de Janeiro 2016 Paralympic Games. The theoreticalmethodological framework of Oral History was used with theoretical support for the concept of event, based on the analysis of an oral source, which were related to the results found in the literature review. Despite being a very successful modality today, the path taken by the boccia was marked by the disbelief in sports for the person with cerebral palsy, the difficulties of participating in international competitions, the lack of specific equipment and the few resources destined to the sport for people with disabilities in the country. His memory shows much more than a path taken by a sport, medals and competitions, since it records part of the history of the Brazilian Paralympic movement. In this way, we consider that the brazilian boccia has created a great legacy, revealed in this work. It is hoped, through this historical outline, to contribute to the research of Paralympic sport, preserving the memory of sports for the person with Cerebral Palsy, especially the boccia.

Keywords: History of sport; Boccia; Cerebral palsy.

\section{Resumen}

El estudio apunta a la aparición de las boccias paralímpicos brasileñas. El deporte escenario para los deportistas con parálisis cerebral y otras discapacidad graves. La pasión del profesor ivaldo Brandão permitió el surgimiento de un deporte extremadamente exitosa. Tiene como 
objetivo investigar el camino de la boccia paralímpica brasileña desde los primeros juegos de parálisis cerebral celebrados en mar del plata, argentina en 1995 hasta los juegos paralimpicos del Río de Janeiro 2016. El marco teórico-metodológico de la Historia Oral se utilizó con apoyo teórico para el concepto de evento, basado en el análisis de una fuente oral, que estaban relacionados con los resultados encontrados en la revisión de la literatura. Por más de ser una modalidad muy exitosa en la actualidad, el camino recorrido por las boccias estuvo marcado por la incredulidad en los deportes para las personas con parálisis cerebral, las dificultades para participar en competencias internacionales, la falta de equipos específicos y los pocos recursos destinados al deporte para personas con discapacidad en el país. Su memoria muestra mucho más que un camino tomado por un deporte, medallas y competiciones, ya que registra parte de la historia del movimiento paralimpicos brasilero. De esta manera, consideramos que la boccia paralímpica brasileña ha desarrollado un gran legado, mostrado en este estudió. Se espera, através de este esquema histórico, contribuir a lá investigación del deporte paralimpico. Preservando la memoria del deporte para la persona con parálisis cerebral, especialmente la boccia paralímpica.

Palabras clave: Historia del deporte; Boccia; Parálisis cerebral.

\section{Introdução}

Em 2016 aconteceu no Rio de Janeiro a realização dos Jogos Olímpicos e Paralímpicos de verão e muitas pessoas tiveram contato com algumas modalidades pouco conhecidas para a maioria da população, como o Goalball, o Rugby em Cadeira de Rodas e a Bocha Paralímpica (Dantas, 2019). Foi um momento espetacular, para o esporte paralímpico, tanto pela exposição da imagem do Comitê Paralímpico Brasileiro - CPB junto à população em geral quanto à divulgação das possibilidades esportivas para as pessoas com deficiência que podiam ver ao vivo ou pela tv modalidades pouco conhecidas e praticadas no país.

O jogo de Bocha Paralímpica teve como local de competição a Arena Carioca 2, com uma área de 23 mil metros quadrados e capacidade para 10 mil pessoas, teve ingressos esgotados e casa lotada durante os finais de semana. Poucos presentes na arena conheciam a bocha paralímpica, mas estavam empolgados com o clima festivo, a oportunidade de ver uma seleção brasileira paralímpica de perto e estar presente em um dos espetáculos esportivos mais importantes da era moderna, motivando e fazendo com que as pessoas se apropriassem dos elementos básicos do movimento paralímpico, mesmo sem entender direito a dinâmica do jogo (Ibid, 2019). 
De aparência simples e infantil no primeiro olhar, o jogo da bocha paralímpica vem ganhando adeptos em todo o Brasil, tanto praticantes quanto espectadores e admiradores, por ser um esporte complexo, rico em situações de jogo, cheio de surpresas, muito desafiador e extremamente estratégico. Acrescido a esses elementos, ainda temos o fato de ser praticado por pessoas com um quadro de disfunção motora severa, o que torna cada partida um espetáculo de superação e de plasticidade corporal (Dantas, 2019).

Nacionalmente, a Associação Nacional de Desporto para o Deficiente - ANDE é a responsável por desenvolver e massificar as modalidades para as pessoas com paralisia cerebral. Atualmente gere a Bocha Paralímpica, o Race Running e o Futebol para Paralisados Cerebrais (Fut 7PC).

No entanto, a modalidade ainda é pouco conhecida da maioria dos brasileiros, apesar da hegemonia de nossos atletas com os excelentes resultados conquistados (Dantas, 2019) com as medalhas de ouro de Dirceu Pinto e Eliseu Santos nos Jogos de Beijing 2008, medalhas de ouro de Dirceu Pinto, Eliseu Santos e Maciel Santos nos Jogos de Londres 2012 e as medalhas de ouro de Evani Calado, Antônio Leme e Evelyn de Oliveira nos Jogos do Rio 2016, além de muitas conquistas nas edições da Copa América e nos Campeonatos Mundiais.

Além de Dirceu Pinto, Eliseu Santos e Maciel Santos, outras pessoas marcaram o desenvolvimento da bocha paralímpica no Brasil. No entanto, a ausência de registros e a escassez de estudos que se dediquem a dar visibilidade a origem dessa modalidade no país, com relação aos primeiros campeonatos, os primeiros materiais utilizados pelos atletas, a formação de árbitros e equipe de classificação, pode produzir a falsa impressão de que elas não tiveram protagonismo. Na perspectiva de dar visibilidade a atuação desses atores, buscaremos reconstruir e preservar suas memórias (Begossi \& Mazo, 2016), principalmente por meio do depoimento oral do professor Ivaldo Brandão Vieira ou simplesmente professor Brandão, uma vez que, ele é o estopim da implementação do futebol de 7PC e da bocha paralímpica no Brasil, fazendo assim, parte da memória social do esporte paralímpico brasileiro.

Tendo em vista este panorama, o objetivo do estudo é investigar o percurso da bocha paralímpica brasileira dos jogos de Mar Del Plata 1995 aos Jogos Paralímpicos Rio 2016. Assim, caminharemos pelo processo da estruturação do esporte para a pessoa com paralisia cerebral e deficiências severas no país em uma época onde a escassez de investimento ao esporte paralímpico era muito presente.

A realização da pesquisa foi pautada nos pressupostos teórico-metodológicos da História Oral com apoio teórico do conceito de acontecimento, buscando apresentar uma 
narrativa histórica de representações do passado e formulando uma versão do já representado (Begossi \& Mazo, 2016). Na medida em que se cria a ponte entre o presente e o passado, se registra uma versão do desenvolvimento da modalidade no campo paradesportivo no país. Na construção desta ponte, não se perde de vista que as grandes conquistas da bocha paralímpica na atualidade foi embasado no passado por nomes que precisam estar registradas na história do esporte paralímpico brasileiro.

\section{Metodologia}

Procurando investigar o percurso da história da bocha paralímpica no Brasil, nossa investigação está sustentada no campo da História do Esporte (Melo \& Fortes, 2010; Vamplew, 2013) com apoio teórico do conceito de acontecimento que se apresenta como instrumento conceitual para compreensão desse percurso (Caldas, 2010). Nesta perspectiva, entendendo que a realidade social é culturalmente construída, utilizaremos das memorias de um dos principais gestores esportivos do país, enquanto sujeito histórico, resgatando suas rememorações por meio de sua prática profissional, acessando informações que não estão registradas em artigos ou documentos de fonte indireta como preconiza Pereira et al. (2018) e, desta forma, também utilizando a História Oral para pautar a elaboração do estudo com base na reconstrução do vivido, estruturada nas lembranças do professor Brandão que é sujeito histórico viva das ações desenvolvidas no campo esportivo da pessoa com PC e deficiências severas.

As memórias contribuem para reconstruir, historicamente, o cenário sociocultural da bocha paralímpica e do esporte paralímpico do Brasil. Para atingir ao objetivo proposto foi realizada uma revisão bibliográfica para obter informações que balizassem as interpretações ao longo do estudo. Contudo, devido aos poucos materiais disponíveis, utilizamos, primordialmente, a fonte oral e foram processadas contemplando as orientações da História Oral (Alberti, 2018).

Todas as informações encontradas foram relacionadas com a revisão bibliográfica disponível e interpretadas com base nesse referencial teórico. Os resultados são apresentados na sequência. 


\section{Resultados e Discussão}

\section{O Pioneirismo de um professor}

Contar a história do esporte para a pessoa com Paralisia Cerebral (PC) no país é falar um pouco da história do professor Brandão. Um olhar mais íntimo da gênese de uma modalidade que vem dando muitas alegrias ao mundo paralímpico brasileiro, contada a partir da história de quem sempre viveu o esporte para a pessoa com deficiência e contribuiu para a massificação e desenvolvimento de muitas modalidades paradesportivas.

Sendo uma das grandes referências na área, o professor Brandão tem trinta e oito anos de experiência e atuação no esporte adaptado e a história de sua vida se mistura em grande parte com a história do esporte para a pessoa com PC no país. Assim, todos os fatos aqui apresentados certamente contribuirão para preencher uma lacuna ainda existente sobre a história ousada e vitoriosa da bocha paralímpica.

Em 1982, foi realizado o I Campeonato Brasileiro para Pessoas com Paralisia Cerebral no Centro Esportivo Miécimo da Silva. A frente da organização do campeonato estava o professor Aldo Miccolis, que prontamente convidou o professor Brandão para participar também da organização. Nessa época, o professor Brandão era diretor de esportes das modalidades convencionais e nunca havia trabalhado com atividades voltadas a pessoa com deficiência. Ele aceitou o convite e jamais imaginária que aquele evento pudesse encaminhar sua vida profissional para outros mares. De acordo com seu depoimento: "No fim do campeonato, estava encantado e apaixonado pelo esporte adaptado. Foram dias que absorvi muitas experiências que mudariam a minha história e a vida de muitas pessoas com deficiência severa no país".

O atletismo foi a modalidade na qual iniciou sua trajetória no esporte adaptado. Era uma época que pouco se conhecia sobre o esporte para pessoa com deficiência e existiam poucos investimentos sociais. Com relação à prática esportiva no Brasil, o professor Brandão, rememorou que "as informações eram escassas, assim sempre trazia muitas informações que absorvia nos eventos que aconteciam fora do país e ao retornar ensinava aos outros profissionais de educação física como deveriam ministrar os treinos para alcançar melhores resultados no atletismo paralímpico".

Nesse período ninguém queria trabalhar com o PC porque eles davam muito trabalho e não existiam muitas atividades sendo desenvolvidas no Brasil para esse público (Dantas, 
2019). Os cuidados com as pessoas com PC podem exigir demandas elevadas em decorrências das sequelas da deficiência (Bukhard, 2013) e de sua topografia. Na bocha paralímpica o quadro clínico geralmente requer altas exigências e uma sobrecarga aos cuidadores e treinadores, com assistência as atividades de vida diária e ao programa de treino.

Quando o movimento esportivo para a pessoa com deficiência começou a se organizar no Brasil, uns queriam trabalhar com os amputados, outros foram trabalhar com os cegos, porque nenhum desses dava trabalho e no final sobraram os PCs. Em seu depoimento, professor Brandão comentou que em 1986, o professor Aldo Miccolis tinha o convidado o para ser o diretor técnico da ANDE, com objetivo de introduzir novas modalidades esportivas para o segmento, dentre elas o Futebol de 7PC.

Em 1988, o professor Brandão foi enviado aos Jogos Paralímpicos de Seoul, onde participou como observador técnico, e ao voltar trouxe muitas informações na bagagem. No entanto, apenas em março de 1989 na Escola de Educação Física da Marinha - Almirante Adalberto Nunes (CEFAN) foram iniciados os primeiros encontros para a formação do primeiro time brasileiro de futebol de 7PC (Gorla \& Nogueira, 2016), três anos após assumir a direção técnica da ANDE.

Seria necessário esperar mais um ciclo paralímpico para que pudessem ser despertadas no país a visão para as diversas modalidades existentes para o PC, como a bocha paralímpica, tinham muitas modalidades interessantes, mas no Brasil não existia profissionais qualificados para se trabalhar com elas. Esse seria um dos grandes desafios a ser vencido!

Rememorando os jogos de Barcelona 1992, o professor Brandão lembra que Sebastião Antônio da Costa Neto - o Tião ganhou uma medalha arremessando o Club e de forma visionária, ele traz o Club para o Brasil. O Tião tinha tido o primeiro contato com o Club apenas na chegada em Barcelona. Declara o professor Brandão que "no início as coisas aconteciam assim: os atletas iam para participar dos Jogos Paralímpicos e acabavam trazendo algumas medalhas, sem muito planejamento e expectativas".

\section{Nos rastros da gênese da bocha paralímpica}

No Brasil, agora tinha um Club, um apenas, o que tinha sido trazido dos Jogos de Barcelona. Assim ele começou a ser colocado nas provas do atletismo na perspectiva de difundir mais uma possibilidade de atividade para o PC, mas com pouco tempo o Club quebrou a parte onde o atleta segurava para fazer os arremessos e como era de madeira machucava bastante e os PCs começaram a reclamar bastante (Dantas, 2019). 
No depoimento do professor Brandão, encontramos informações que os atletas com PC diziam que estavam sendo explorados porque só colocavam material ruim para as competições. Eles não entendiam que esse era o único material disponível no país, ou usava, ou não se tinham as provas. Os poucos atletas que tinham reclamavam constantemente, principalmente a atleta Márcia da APARU/MG alegando que só os PCs utilizavam material ruim e que sempre eram desprestigiados nas competições. É provável que, por sua vez, tal fato repercutia também no baixo índice de pessoas com PC participando no esporte paralímpico inibindo, consequentemente, seu desenvolvimento no país.

Nesse período ia acontecer os Jogos de Mar Del Plata e o Brasil tinha sido convidado para participar da competição da bocha paralímpica mas não havia uma equipe no país. Segundo o professor Brandão, ele convida o professor José Henrique para ir a Argentina como técnico da seleção brasileira. O professor José Henrique não tinha informações sobre a modalidade e estava indo principalmente para conhecer e trazer os conhecimentos necessários para implementar a modalidade na volta ao país. Tínhamos o técnico, agora faltavam os atletas.

Acontecia ali a primeira convocação do técnico da Seleção Brasileira de Bocha Paralímpica. Em seu relato, o professor Brandão narrou que precisava agora convocar a atleta e chamou a Márcia da APARU/MG e disse: "Você reclama de tudo, me deixa constrangido enquanto diretor técnico da ANDE mas vou levar você para Mar Del Plata". Ela pensava que ia para participar da prova do atletismo e questionou se iria jogar com o Club todo quebrado ou se já haviam comprado um novo. Foi quando o professor Brandão respondeu: "Não! Você vai jogar bocha! Quando eu chegar no avião digo o que é e como se joga a bocha”.

O depoimento do professor Brandão aponta como foi realizado o primeiro treino de bocha. Segundo ele agora estavam convocados técnico e atleta. "Foi no avião que dei as primeiras orientações para a Seleção Brasileira. Pegamos umas bolinhas de papel e comecei a explicar para o técnico e para a atleta o que era e como se jogava a bocha”. Três horas de voo entre São Paulo e a Argentina, foi o tempo que usado para fazer as primeiras explicações. Durante o voo rememora o professor Brandão que perguntou ao professor Perguntei ao professor José Henrique: "Está entendendo? Você vai para lá e veja tudo o que está acontecendo". "Nessa época a Argentina era muito avançada na modalidade e nós não sabíamos nada. Precisávamos absorver ao máximo para divulgar a modalidade no Brasil”, ainda relatou.

É com esse espirito de ampliação e de forma bastante inusitada, que em 1995, é formada a primeira Seleção Brasileira de Bocha Paralímpica, antes mesmo de existirem 
atletas treinando em território nacional e até mesmo da modalidade ser conhecida e desenvolvida por algum clube no país. Tudo aconteceu durante os I Jogos Paradesportivos de Paralisados Cerebrais realizado em Mar Del Plata, na Argentina. A delegação Brasileira recebeu o convite para conhecer a Bocha e elegeu uma atleta com PC do atletismo para participar da competição, (Vieira \& Campeão, 2012).

A Márcia chegou na competição, fez a classificação, fez adaptação, começou a treinar e foi para os jogos. Relembra o professor Brandão que para participar da competição tiveram que pedir material emprestado. Na classificação funcional, ficaram apenas olhando porque nada sabiam sobre os critérios de elegibilidade, apenas tinham levado atleta com PC e torciam para que fosse legível. As coisas foram dando certo e a Márcia chegou até a fase final. No jogo da decisão, que aconteceu contra o melhor atleta da Argentina ela jogou as bochas e fomos campeões. Ainda narra em seu depoimento: "para você ver como a bocha é imprevisível".

Nesse momento nascia a história da bocha paralímpica do Brasil!

Tornou-se notório em sua narrativa que a gênese da bocha no Brasil foi marcada pela necessidade de ampliar as possibilidades esportivas para a pessoa com PC. Aproveitar as oportunidades de um movimento esportivo que se iniciava nas Américas foi o grande estopim para o desenvolvimento desta modalidade no país, mesmo com as dificuldades encontradas pela falta de capacitação técnica e de materiais adequados.

\section{Trilhando as dificuldades da implementação}

Em 1996, um ano depois dos Jogos de Mar Del Plata, coube ao professor Brandão a divulgação e implantação da modalidade no país. Através da ANDE, é lançado o Projeto "Boccia para portadores de paralisia cerebral severa" em Curitiba/PR (Vieira \& Campeão, 2012; Herbst, Mascarenhas \& Slonski, 2013; Dantas, 2019). Ao rememorar esse período o professor Brandão informa que para desenvolver a modalidade, convidou o professor José Luiz Campos para fazer uma clínica aqui no Brasil e paralelo foi realizado o primeiro Campeonato Brasileiro de bocha em Curitiba. A ideia inicial era apenas trazer a clínica, mas não se liberava recursos para se fazer apenas o curso. Nesse período os recursos eram liberados exclusivamente para organização de eventos esportivos.

A narrativa aponta a maneira inusitada para poder implementar a modalidade no país. No depoimento do professor Brandão percebe-se a necessidade de formar uma equipe de técnicos qualificados e para isso foi necessário ousar! 
O professor Brandão repassou sua sensação de realizar o evento, na medida em que foi revivendo em suas memórias naqueles momentos:

Nessa época nem tínhamos atletas suficientes no Brasil para realizar uma competição. [...] Realizei um campeonato fictício, única e exclusivamente para obter recursos para o desenvolvimento da bocha no Brasil. [...] Juntei alguns professores que já estavam envolvidos com o movimento, alguns indivíduos com PC e reuni todos numa sala do Hotel Jaraguá, montamos uma quadra de bocha e ficamos das $15 \mathrm{~h}$ às $03 \mathrm{~h}$ da madrugada escutando e aprendendo sobre a modalidade com professor José Luiz Campos. [...] Todos ficaram bastante motivados, participaram professores de dez clubes, sendo cinco do Rio de Janeiro, dois do Paraná, um de São Paulo, um de Minas e um do Mato Grosso do Sul.

Ainda em 1996, aconteceu o IV Campeonato Brasileiro de Paralisados Cerebrais realizado em Vitoria/ES. Para o professor Brandão foi a oportunidade de implementar a modalidade da bocha paralímpica no evento, mesmo sem possuir material para a prática esportiva. Para sanar o problema da falta de material, ele rememora que comprou bolas de futebol pequenas, comprou tinta azul, vermelha e branca e pintou as bolas fazendo o primeiro kit de bocha que foi utilizado em uma competição no país. Desse momento ele fala em seu depoimento: "Como tudo não é perfeito, a tinta não pegou direito nas bolas e elas largavam facilmente ainda nos primeiros lançamentos. As bolas da bocha que produzimos ficaram um festa"! Mesmo assim, a competição foi realizada durante o evento, sendo de fato a primeira competição de bocha paralímpica no país, mesmo ainda que realizada na improvisação.

$\mathrm{O}$ entusiasmo e a seriedade com que vivia o esporte para a pessoa com PC foram características que, provavelmente, também impulsionaram o professor Brandão a não desistir. Era necessário agora suprir a falta de material adequado a prática no Brasil. Não dava para continuar pintando bolas de futebol e realizando as competições. Dessa forma a ANDE realizou uma pesquisa e descobriu que na Dinamarca vendia as bolas da bocha paralímpica. $\mathrm{O}$ professor Brandão fez um projeto para poder importar o material e alavancar $\mathrm{o}$ desenvolvimento da modalidade no país.

Ele foi revivendo esse momento e trazendo memórias de um período extremamente difícil para a implementação da modalidade:

Lembro perfeitamente do dia que o projeto foi aprovado e as bolas da bocha paralímpica foram compradas e importadas da Dinamarca. [...] Só não se esperava que elas ficariam presas na polícia federal. Foram comprados 10 kits e todos ficaram presos! [...] Por muito tempo tentou-se liberar o material. Passaram 06 meses, 08 meses e daí, finalmente, elas foram liberadas. [...] Agora surgia outro problema, a 
taxa de armazenamento das bolas na polícia federal era tão alta que já não compensava retirar o material e os kits foram deixados por lá mesmo.

Pela narrativa apresentada é evidente que nesse período a falta de material no país ainda era um grande problema para o desenvolvimento da modalidade, situação que precisava ser corrigida para alavancar as possibilidades de massificação e ampliação das atividades desenvolvidas com os atletas com PC.

Durante o depoimento rememora o professor Brandão que tecnicamente a seleção brasileira ainda era muito fraca e nesse período só levava pancada porque não tinha volume de treinamento nos clubes e nenhuma afinidade com o processo. Foi quando apareceu o Sr. Décio Baroni, em Maringá, ele pegou uma bola que tinha sido trazida de uma competição internacional e disse que poderia fabricar aqui no Brasil. Segundo o professor Brandão, ele disse ao Sr. Décio: "Compro todo o material que você fabricar. Se fizer uma bola, eu fico! Se fizer cem bolas, fico também!" Daí surgiu a primeira fábrica de bolas de bocha paralímpica no país, a Bocha Brasil.

Nesse período a ANDE comprava todas as bolas de bocha paralímpica produzidas pela Bocha Brasil e distribuía os kits aos clubes na perspectiva de fomentar a modalidade e ampliar a quantidade de atletas praticando a modalidade. Depois desse pontapé inicial, a ANDE passa a investir nas competições regionais e na construção do campeonato brasileiro. A seleção brasileira aumenta o número de participações em competições internacionais, mas os resultados ainda são inexpressíveis (Dantas, 2019).

\section{Neste país tudo que se planta, colhe.}

O professor Brandão relatou que em 2001, foi realizado o II Campeonato de Brasileiro de Bocha em Petrópolis/RJ, dessa vez com jogos entre atletas diferente do que aconteceu em 1996. Nessa competição foi realizado um curso de arbitragem que participaram Alexsandro Lautterbach, Erinaldo Chagas e Artur Cruz e onde Cláudio Diehl começou a conhecer o processo da classificação funcional. Todos esses desempenham papeis extremamente importantes na bocha paralímpica na atualidade.

As bolas da bocha paralímpica já não eram mais problemas, já se tinha muito material no Brasil, as que eram compradas durante as competições fora do país com a seleção brasileira e as bolas que o Sr. Décio já fabricava aqui (Dantas, 2019). Segundo o professor Brandão, ainda era necessário ter resultados expressivos nas competições internacionais. 
Nesse período, foi realizado um planejamento estratégico para o futebol de 7PC e para a bocha. Cada modalidade devia voltar de Atenas 2004 com uma medalha.

Tudo ia bem até que aconteceu um problema, os atletas da bocha paralímpica não conseguiram ir para uma competição na Nova Zelândia e essa competição era classificatória para os Jogos Paralímpicos. O dinheiro para a viagem não saiu e a seleção brasileira não embarcou para a disputa das vagas. Perdemos a possibilidade de classificar alguém para ir para Atenas 2004 e o planejamento estratégico da bocha paralímpica tinha esbarrado na falta de recursos, já o futebol tinha garantido a participação em Atenas.

A falta de políticas públicas, especificas para o esporte paralímpico é abordado por Reis (2016) que aponta a lei $\mathrm{n}^{\circ} 11.438$ de 29 de dezembro de 2006 de Incentivo ao esporte, a lei 10.264 de 16 de julho de 2001, chamada de lei Agnelo/Piva e a lei no 10.891 de 09 de julho de 2004, conhecida como bolsa atleta, como o principal suporte para clubes e atletas na atualidade. Certamente a falta dessa estrutura dificultou o desenvolvimento mais rápido e ampliado na origem do esporte para as pessoas com deficiência no Brasil.

Antes do surgimento do CPB em 1995, a ANDE era responsável pelos desportos praticados por todas as áreas de deficiência. A ANDE foi o embrião do CPB e depois do seu surgimento coube a ANDE fomentar e desenvolver o desporto para pessoas com paralisia cerebral (Miranda, 2011).

Rememora o professor Brandão que na década entre 2000 a 2010, havia comprado uma briga muito grande com o CPB. O Comitê passou a receber os repasses das Loterias Caixa, mas não queria enviar recursos para a ANDE, que já era o responsável nacionalmente para desenvolver os esportes para as pessoas com Paralisia Cerebral. O CPB fazia um investimento muito grande nos esportes para os cegos, lá não faltava recursos e é exatamente por isso que eles são tão desenvolvidos atualmente.

Em depoimento, o professor Brandão lembra que foi no período da briga com o CPB que a ANDE mais produziu:

Chamamos o professor José Fernandes lá da Universidade Federal do Rio de Janeiro, montamos um grupo de avaliação e começamos a trabalhar pesado com os PCs. [...] Todos os outros, os deficientes visuais, os físicos e os intelectuais, faziam as avaliações na UNIFESP em São Paulo. [...] Só os PCs faziam as avaliações no Rio de Janeiro e não queríamos nenhuma aproximação com a UNIFESP, era necessário mostrar que a ANDE também produzia conhecimento e não era o patinho feio do movimento paralímpico como todos achavam. 
Em seu depoimento o professor Brandão lembra que era necessário criar um padrão de treinamento ao nível nacional, todo mundo que trabalhasse com o esporte para o PC precisaria ter acesso as melhores informações e seguir os padrões internacionais de competição. É nessa década que se cria o curso de capacitação técnica da ANDE e as competições sempre seguiram criteriosamente as demandas internacionais da modalidade. O PC chegava atrasado na câmara de chamada e já recebia a informação que ele não podia competir. Ou se adequava as regras da modalidade, ou não jogava. Ainda disse o professor Brandão: "desde que começamos com a modalidade todos tinham que seguir as regras internacionais. A câmara de chamada, a competição, tudo que você tinha lá fora você tinha nas competições aqui”.

A narrativa aponta um crescimento evidenciado pela estruturação administrativa da prática do esporte paralímpico no Brasil (Miranda, 2011), o que corrobora com o estudo de Araújo (1998), que aponta que o movimento do desporto para pessoas com deficiência, em âmbito nacional, sempre buscou a sua institucionalização, desde a sua origem.

Portugal era nesse período a referência mundial na modalidade (Dantas, 2019). Então o professor Brandão entrou em contato com o presidente do Comitê Paralímpico Português e organizou um intercâmbio, pegou o pessoal todo da comissão da seleção brasileira e enviou para Portugal. Era preciso ver como a seleção portuguesa treinava e jogava. Era preciso jogar com eles para melhorar o nível técnico de nossos atletas.

Segundo o professor Brandão, o CPB não acreditava no trabalho que estava sendo realizado pela ANDE. Contudo, chegou a hora dos Jogos Paralímpicos de Beijing 2008. O sucesso em Beijing era garantido, já que o planejamento e o trabalho realizado no ciclo de Atenas 2004 para Bejim 2008 estava perfeito. O Brasil tinha passado pelo processo de divulgação e massificação da bocha paralímpica e nesse período já começaram a aparecer os primeiros resultados expressivos internacionalmente, mesmo sem muitos recursos.

E lá foram todos para Beijing!

\section{A colheita das primeiras medalhas de ouro}

Em seu depoimento o professor Brandão lembra que a chegada a Beijing foi cheia de surpresas:

Nem todo mundo da ANDE conseguiu credenciamento e o professor Brandão foi novamente ousado e criativo. [...] Falei com o Joaquim de Portugal que era o coordenador da modalidade antigamente. [...] Ele nos deu Day Pass escrito em português para ele e para os que estavam sem credenciamento da ANDE. [...] O Day 
Pass era o número 6, aquele que você pode entrar em qualquer lugar. [...] Percebi que os chineses não sabiam português, olhavam o número 6 e deixavam entrar. [...] Assim entramos em todas as arenas, todos os dias.

Segundo o professor Brandão, eles ainda estavam brigados com o CPB e se não tivesse contatado o Joaquim, estariam sem credenciamento, transporte e deixados para trás. Enquanto os principais representantes do CPB frequentavam diariamente os lounges vip, do Ninho dos Pássaros, Estádio onde foi realizado a abertura dos jogos.

Pela narrativa apresentada o Day Pass foi realmente um dos grandes sucessos da ANDE nos jogos de Beijing, porque tiveram acesso a todos os locais, desde o lounge vip, do Ninho dos Pássaros, a família paralímpica brasileira. Onde estava o CPB eles também estavam, comendo, bebendo e conversando, fazendo articulações e ampliando a network. Para aumentar a ousadia, o Day Pass era para uso apenas no primeiro dia, mas como os chineses não sabiam o português eles usaram todos os dias de Jogos Paralímpicos.

Rememora o professor Brandão que nas Paralimpíadas de Beijing 2008, a Seleção Brasileira tem seus resultados mais expressivos, no individual BC4 com Dirceu Pinto e Eliseu dos Santos, que conquistaram a medalha de ouro e bronze respectivamente e no pares BC4, também com Dirceu Pinto e Eliseu dos Santos, conquistaram a primeira colocação dando início a era de ouro dessa modalidade.

Em seu depoimento o professor Brandão relembra que durante os jogos, a Ádria dos Santos, atleta do atletismo, perdeu duas medalhas que estavam dentro dos planos do CPB para o Brasil ficar entre os dez primeiros colocados no resultado final dos jogos. E numa dessas visitas a família paralímpica ele escutou uma conversa onde diziam que as medalhas ganhas na bocha paralímpica substituiriam as medalhas perdidas pela Ádria. Nesse momento, o professor Brandão se encheu de emoção, na medida em que foi revivendo em suas memórias aqueles momentos:

Levantei e gritei: Essas medalhas substituem nada, podia até não estar no planejamento de vocês, mas já estava no nosso. [...] Foi um "pega pra capar", porque estavam desprezando a conquista da bocha paralímpica. [...] Ninguém contava com as medalhas da Bocha em Bejim.

Em sua narrativa o professor Brandão lembra que a ANDE sai dos jogos com a moral elevada! Foi uma conquista muito festejada nos clubes. Era necessário continuar crescendo e construir uma equipe ainda mais competitiva para o próximo ciclo paralímpico. 
Segundo Miranda (2011), o país teve o melhor resultado de todas as participações no Jogos de Pequim 2008. A delegação brasileira trouxe para casa 47 medalhas, 16 de ouro, 14 de prata e 17 de bronze; posicionando o país em $9^{\circ}$ no quadro geral de medalhas e três delas, da bocha paralímpica.

\section{As medalhas de Londres e do Rio}

Para o professor Brandão era necessário investir no desenvolvimento e expansão da modalidade. Em seu discurso afirma que através da ANDE criou em 2008 o curso de capacitação técnica dos profissionais envolvidos com a modalidade, além de convidar clubes que ainda não desenvolviam a bocha paralímpica para participar do evento, objetivando ampliar e divulgar o esporte em todos os estados do país.

Chega a hora de Londres 2012! Os jogos aconteceram entre os dias 02 e 08 de setembro no Exhibition Centre London. Esse é o auge da trajetória da modalidade até o momento, relembra o professor Brandão e retrata um pouco de suas memorias:

Foi exatamente em Londres que a bocha paralímpica do Brasil faz o melhor índice técnico de todos os esportes que o CPB enviou para essa missão. [...] Índice com a quantidade de medalhas que nenhum país nunca mais conseguiu. [...] Novamente, no individual BC4, Dirceu Pinto e Eliseu dos Santos, repetiram os resultados dos últimos jogos e conquistaram a medalha de ouro e bronze respectivamente. [...] Na competição de pares $\mathrm{BC} 4$, os dois, conquistaram a medalha de ouro se tornando bicampeões. [...] $\mathrm{E}$ Dirceu Pinto, bicampeão no individual. [...] Só que dessa vez tivemos a medalha de ouro de Maciel Santos no individual BC2.

A Seleção Brasileira tem resultados melhores que Beijing 2008, colhendo o trabalho estruturado e planejado pela ANDE aos comandos do professor Brandão. Em seu depoimento ele rememora que tinha feito um planejamento para que em dez anos o Brasil fosse a referencial mundial. Ele fala: "Depois de Londres éramos hegemônicos na classe BC4 e BC2. Nas competições na América não perdíamos mais para ninguém. Todos passaram a nos ter como referência. Todos"!

Nos Jogos Rio de Janeiro 2016, a seleção brasileira de bocha conquistou medalhas em duas oportunidades. Nas categorias de duplas mistas BC3 tivemos a inédita medalha de ouro com Antônio Leme, Evani Soares e Evelyn de Oliveira venceram a República da Coreia por 5x2. Na dupla BC4, os atletas brasileiros Dirceu Pinto, Eliseu dos Santos e Marcelo Santos deixaram escapar o tri na competição e ficaram com a prata. 


\section{Considerações Finais}

O professor Ivaldo Brandão Vieira compartilhou os principais momentos da estruturação da bocha paralímpica no Brasil. Através de suas rememorações, evidenciamos uma construção ousada e vitoriosa no percurso da modalidade dos Jogos de Mar Del Plata 1995 aos Jogos do Rio de Janeiro 2016, sendo carregadas de muitas memórias e vivências. Do mesmo modo, sua história marca um período importante na história do esporte paralímpico brasileiro, através de seus feitos.

Neste sentido, registrar suas lembranças, rememorando os caminhos percorridos é uma forma de preservar uma versão da história do esporte para as pessoas com PC no Brasil. Foi deixado um legado que buscamos dar visibilidade por meio desta narrativa histórica.

Existem muitas lacunas a serem supridas e para isso, para avançar nos rastros da história da pessoa com PC, com deficiência severa e do esporte paralímpico, é necessário ampliar o acesso aos documentos da época, além de analisar outras fontes orais que participaram desse período e ainda se encontram vivas e disponíveis.

Nesses vinte e cinco anos no Brasil, a bocha paralímpica já alcançou um patamar de respeito a nível internacional. Contudo, muito terreno ainda precisa ser cultivado para que novos atletas possam surgir.

A ampliação do acesso a prática esportiva para pessoas com deficiência severa, a construção de conhecimento e a divulgação de informações geradas pelos anos de tentativa de acerto e erro, pelas pesquisas desenvolvidas por parceiros são o alicerce de tudo que vem sendo construído.

A ANDE vem desenvolvendo um trabalho pioneiro e bastante sério que em breve nos dará ainda muito mais pano para dar continuidade a escrever a história vitoriosa da modalidade no país.

\section{Referências}

Alberti, V. (2018). Manual de história oral. Editora FGV.

Araújo, PFD. (1997). Desporto adaptado no Brasil: origem, institucionalização e atualidade. Tese apresentada ao programa de pósgraduação da Faculdade de Educação Física da Universidade Estadual de Campinas/Unicamp. 
Begossi, T. D., \& Mazo, J. Z. (2016). O percurso esportivo das mulheres pioneiras no cenário paralímpico sul-rio-grandense. Revista Brasileira de Ciência e Movimento, 24(4), 143-155. Burkhard, A. (2013). A different life: caring for an adolescent or young adult with severe cerebral palsy. Journal of pediatric nursing, 28(4), 357-363.

Caldas, PSP. (2010). Teoria e Prática da Metodologia da Pesquisa Histórica: Reflexões sobre uma Experiência Didática. Journal of Theory of History. 3(1). DOI:

https://doi.org/10.5216/rth.v3i1.28628

Dantas, M. J. B. (2019). História da bocha paralímpica no brasil. Em M. J. B. Dantas, T. L. F. S. Dantas, C. D. Nogueira \& J. I. Gorla (Ed.), Bocha paralímpica: história, iniciação e avaliação (pp. 13 - 24). Curitiba, PR: CRV.

de Melo, V. A., \& Fortes, R. (2010). História do esporte: panorama e perspectivas. Fronteiras, 12(22), 11-35.

Gorla, J. I., \& Nogueira, C. D. (2016). Esporte adaptado e formação de recursos humanos: experiências construídas na área. Conexões: Educação Física, Esporte e Saúde, 14(2), 158164.

Herbst, D. M., Mascarenhas, L. P., \& Slonski, E. C. (2013). A história do bocha paralímpico no Brasil e sua evolução como esporte de alto rendimento. Fiep Bulletin.

Miranda, T. J. (2011). Comitê Paralímpico Brasileiro= 15 anos de história.

Pereira, AS et al. (2018). Metodologia da pesquisa científica. [e-book]. Santa Maria. Ed. UAB/NTE/UFSM. Acesso em: 9 maio 2020. Disponível em: https://repositorio.ufsm.br/bitstream/handle/1/15824/Lic_Computacao_MetodologiaPesquisa-Cientifica.pdf?sequence $=1$.

Reis, R. E. (2016). Políticas Públicas para o Esporte Paralímpico Brasileiro. LICERE - Revista Do Programa De Pós-graduação Interdisciplinar Em Estudos Do Lazer, 19(2), 428.

Recuperado de https://periodicos.ufmg.br/index.php/licere/article/view/1255 
Vamplew, W. (2013). História do esporte no cenário internacional: visão geral. Tempo, 19(34), 5-17.

Vieira I.B., Campeão M. S. (2012). Bocha Paralímpica. Em M. T Mello \& C. Winckler (Ed), Esporte paralímpico (pp. 83-91). São Paulo, SP: Atheneu.

\section{Porcentagem de contribuição de cada autor no manuscrito}

Matheus Jancy Bezerra Dantas - 40\%

Thaísa Lucas Filgueira Souza Dantas - 30\%

José Irineu Gorla - 30\% 